
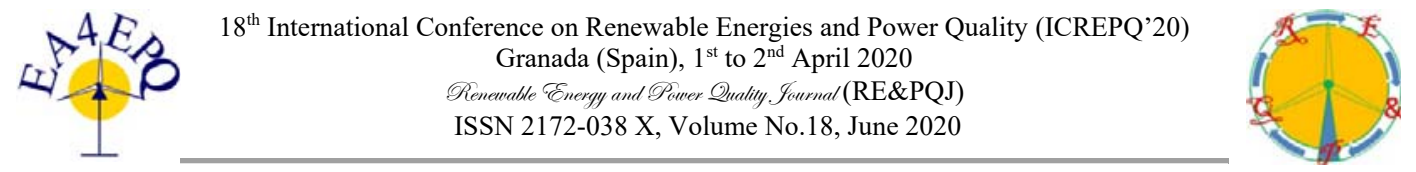

\title{
Hybrid Switch with Tungsten-clad Copper Contacts for Arc-free On/Off Switching up to DC 400 A
}

\author{
K. Yasuoka, Y. Yamada, and M. Chen \\ Department of Electrical Engineering \\ Tokyo Institute of Technology \\ Meguro-ku, Tokyo, 152-8552 (Japan) \\ Phone/Fax number: +81 35734 2185, e-mail: yasuoka@ee.titech.ac.jp
}

\begin{abstract}
Direct current (DC) switches are one of the key components of DC power distribution systems. During the closing and opening periods of the switch, arc discharges are generated causing contact erosion and a reduction of dielectric strength between the contacts. A hybrid DC switch, consisting of mechanical contacts, semiconductor devices, and metal-oxide varistors, can shorten the arc duration; however, a short duration arc still causes contact erosion and induces a reignition of the arc. Arc-free DC switching up to $400 \mathrm{~A}$ for closing and opening periods is demonstrated using tungsten-clad copper contacts and a SiC-MOSFET module. The tungsten part of the contacts increases the boiling voltage of the latter, and the copper part decreases the maximum temperature at the contact spot. Both parts are crucial to achieving arc-free switching.
\end{abstract}

Key words. Hybrid DC switch, Arc-free, Tungsten-clad, SiC-MOSFET, Molten-metal bridge

\section{Introduction}

Direct current (DC) power distribution is the preferred topology for data centers, commercial buildings [1], photovoltaic power stations, electric vehicle charging stations [2], and the electric power systems of marine vessels [3]. Mechanical switches can conduct high currents with low losses. During the opening period, an arc discharge is generated between the contacts. In contrast to alternating current (AC) systems, there is no periodic zerocrossing of the current in DC systems; therefore, the arc discharge is extinguished by increasing the arc voltage above the circuit voltage. The arc duration exceeds $10 \mathrm{~ms}$, and the contact surfaces are severely eroded.

Alternatively, a power semiconductor device can be used as a DC switch. However, the conduction loss is high, and thus, a large heat sink is needed to cool the device. A hybrid DC switch is proposed to combine the advantages of both the mechanical and semiconductor switches, providing a low on-state loss and a reduced arc-erosion [4]. In the conventional hybrid DC switches, semiconductor devices are turned on by the voltage of the arc discharge generated between the contacts. Although the duration of the arc discharge is shorter than that of classical mechanical switches, the arc discharge nevertheless causes contact erosion [5] and degradation of insulation recovery
[6]. Arc-free switching has been demonstrated at up to $200 \mathrm{~V}$ and 7 A [7]; however, a DC switch for the higher voltage and current range is needed for DC power distribution systems.

The arc discharge originates when the contact voltage exceeds the boiling voltage of the contact material [8]. We have demonstrated an arc-free current interruption using two-pole contacts of tungsten material, of which the boiling voltage is $2.1 \mathrm{~V}$, with a SiC-MOSFET module. The maximum arc-free current was $140 \mathrm{~A}$ [9], which is limited by the instability of the molten bridges generated between the contacts. In this study, to realize a high boiling voltage combined with low on-state energy loss, we tested tungsten-clad copper contacts with a SiCMOSFET device that had low turn-on resistance. The arc-free on/off switching was achieved up to the current range of $400 \mathrm{~A}$ DC.

\section{Hybrid switch and arc-free operation}

The hybrid DC switch can be a key device and a potential isolator for a micro DC grid. The typical circuit diagram is shown in Fig. 1. The closing and opening processes of the hybrid switch are explained as follows.

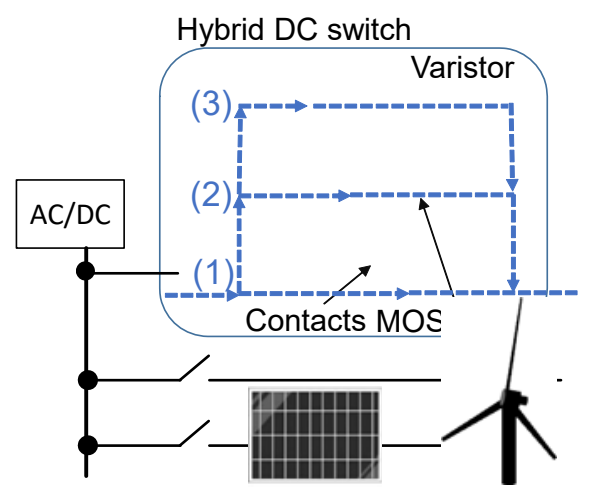

Fig. 1. Basic operation of the hybrid DC switch: (1) Steady-state operation, (2) current commutation from contacts to MOSFET, (3) circuit energy dissipation at varistor.

In the closing process, the MOSFET is turned on first, and the contacts are opened. Consequently, the circuit current flows into the MOSFET, which has a turn-on 
voltage that is the same value as the contact voltage. If the turn voltage is lower than the arc voltage in atmospheric air [10], no arc discharge is generated during the closing process. Then, the contacts close to bypass the conduction loss of the MOSFET.

In steady-state operation, the current flows through the contacts as indicated by pass (1). In the opening process, the contacts open, and then, the contact voltage gradually increases owing to the reduction of contact force and the increase of temperatue at the contadct spots. If the contact voltage exceeds the boiling voltage of the contact material, an arc discharge occurs between the contacts. The contact current is then commutated to the MOSFET as shown in pass (2). After the insulation strength of the contacts recoveres, the MOSFET is turned off, and the current is commutated to the metal oxide varistor (MOV) as shown in pass (3). After the residual circuit energy is absorbed by the varistor, the opening process ends, typically within a few milliseconds. The duration of the arc discharge is in the order of hundreds of microseconds, which is a short duration compared to that of the mechanical switch. However, the contact surface is eroded and the recovery time of the insulation between the contacts decreases [6].

An equivalent circuit of the current commutation loop is shown in Fig. 2. The condition for arc-free commutation is expressed by equation (1), where $V_{b}$ is the boiling voltage, $v_{c}(\mathrm{t})$ is contact voltage, $r_{\text {on }}$ is the turn-on resistance of the MOSFET, $i(t)$ is the commutation current, and $R$ and $L_{\mathrm{r}}$ are loop resistance and inductance, respectively.

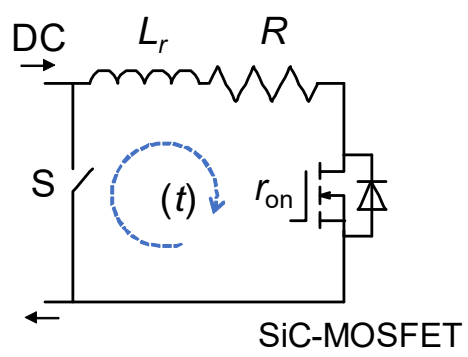

Fig. 2 Equivalent commutation circuit of a hybrid switch.

$$
\begin{gathered}
V_{b} \geq v_{c}(t)=L_{r} \cdot \frac{d i(t)}{d x}+\left(R+r_{o n}\right) \cdot i(t) \\
T_{\text {max }}=\sqrt{\frac{V_{c}^{2}}{4 L}+T_{0}^{2}}
\end{gathered}
$$

The boiling voltages and other material properties of copper and tungsten are shown in Table I. The melting and boiling voltages are calculated by equation (2) given by Holm [8], where $T_{\max }$ is the maximum surface temperature, $V_{c}$ is contact voltage, $L$ is the Lorentz number, and $T_{0}$ is room temperature. If the residual inductance is neglected and the turn-on resistance of the MOSFET is $3.6 \mathrm{~m} \Omega$, the maximum arc-free currents of copper and tungsten are 222 $\mathrm{A}$ and $583 \mathrm{~A}$, respectively. In addition, the selection of a contact material having a high boiling temperature, to remove the Joule heat on the contact spots is important to eliminate the arc generation. Therefore, a tungsten electrode of $1 \mathrm{~mm}$ was cladded onto a copper electrode to form the tungsten-clad copper contacts.

Table I. - Material properties of copper and tungsten [8]

\begin{tabular}{|c|c|c|c|c|c|}
\hline & $\begin{array}{c}\text { Melting } \\
\text { voltage[ } \\
\text { V] }\end{array}$ & $\begin{array}{c}\text { Boiling } \\
\text { voltage } \\
{[\mathrm{V}]}\end{array}$ & $\begin{array}{c}\text { Resistivity } \\
{[\Omega \mathrm{m}]}\end{array}$ & $\begin{array}{c}\text { Thermal } \\
\text { conductivity } \\
{[\mathrm{W} / \mathrm{m} / \mathrm{K}]}\end{array}$ & $\begin{array}{c}\text { Young's } \\
\text { modulus } \\
{\left[\mathrm{N} / \mathrm{m}^{2}\right]}\end{array}$ \\
\hline $\mathrm{Cu}$ & 0.4 & 0.8 & $1.7 \mathrm{e}^{-8}$ & 398 & $1.1 \mathrm{e}^{11}$ \\
\hline $\mathrm{W}$ & 1.1 & 2.1 & $5.3 \mathrm{e}^{-8}$ & 178 & $3.4 \mathrm{e}^{11}$ \\
\hline
\end{tabular}

\section{Experimental Setup}

The developed hybrid DC switch consists of tungstenclad copper contacts, a SiC-MOSFET module (Cree, CAS325M12HM2, $1200 \mathrm{~V}, 444 \mathrm{~A}, 3.6 \mathrm{~m} \Omega$ ), and metaloxide varistors (ERZE, 14A681, $1120 \mathrm{~V}$ ), in atmospheric conditions. Fig. 3(a) shows the tungsten-clad copper contact. The tungsten layer is $1 \mathrm{~mm}$ thick, and the copper bulk is $14 \mathrm{~mm}$ long. The diameter is $10 \mathrm{~mm}$. Fig. 3(b) shows the piezo actuator (MTKK 16S400F170R, 400 $\mu \mathrm{m})$, and Fig. 3(c) shows the driving circuit of the actuator.

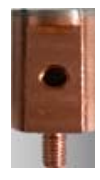

W clad Cu contact

(a)

MOSFET1

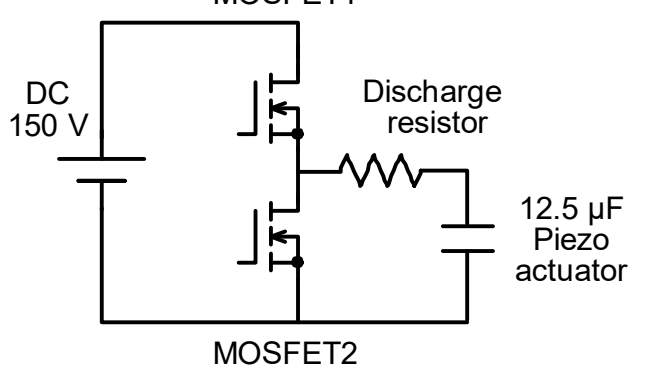

(c)

Fig. 3 (a) Tungsten-clad copper contact, (b) piezo actuator, and (c) driving circuit of the actuator.

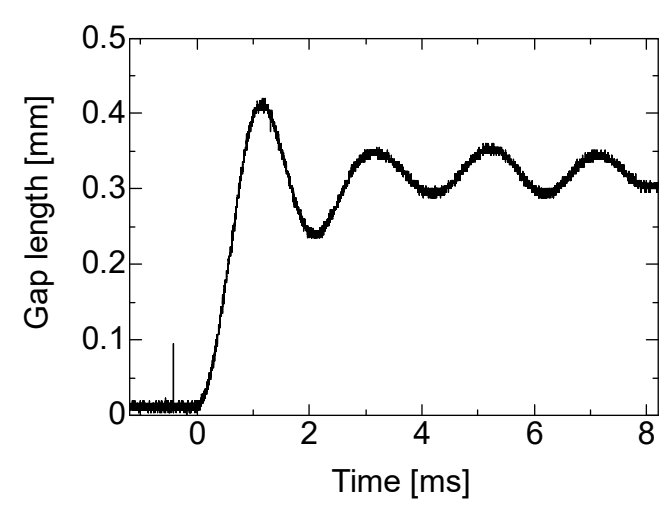

Fig. 4 Time-varying gap length between the contacts of the hybrid DC switch.

The movable contact was fixed to the top of the actuator. By turning on MOSFET1, a voltage of $150 \mathrm{~V}$ was applied to the actuator, after which the actuator expanded. 
The contact force of $43 \mathrm{~N}$ was applied between the contacts, while the gap length at the opening period was set to $300 \mu \mathrm{m}$. After turning off MOSFET1, MOSFET2 was turned on; then, the charge stored in the actuator was discharged at the time constant determined by the discharge resistor. The gap length between the contacts was measured by a laser displacement sensor (KEYENCE, LK-H055, LK-G600V). The gap length oscillated as shown in Fig. 4. The maximum gap length of $0.42 \mathrm{~mm}$ was obtained at $1.2 \mathrm{~ms}$.

Fig. 5 shows the experimental circuit for the hybrid switch. The maximum voltage and current of the power source were $20 \mathrm{~V}$ and $800 \mathrm{~A}$, respectively.

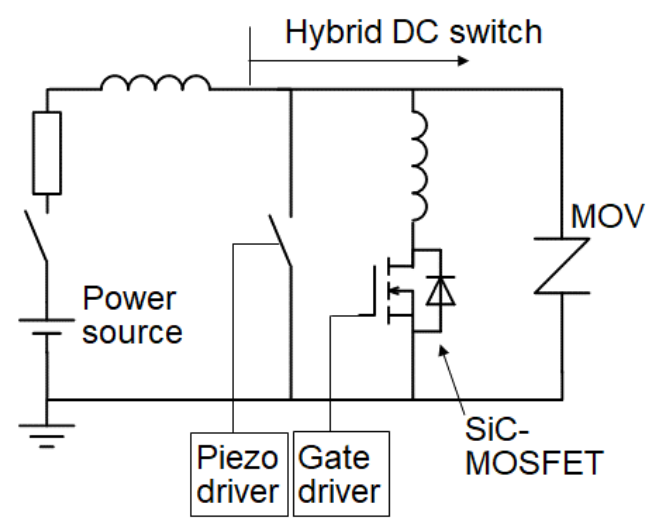

Fig. 5 Experimental setup for the hybrid DC switch.

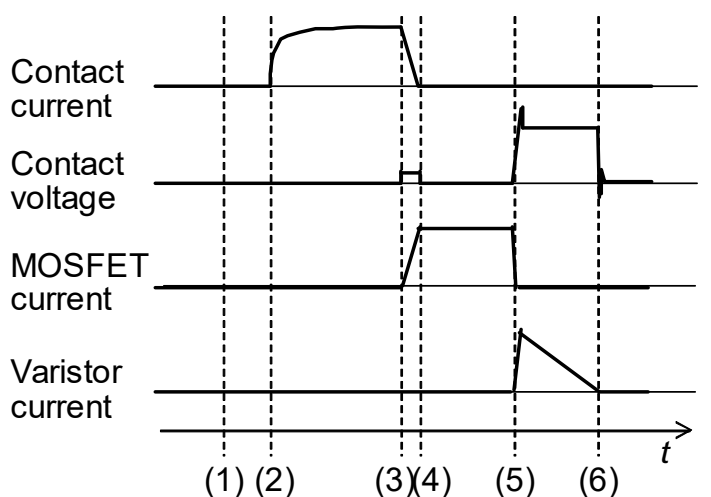

Fig. 6 Interrupting sequence.

The opening sequence of the hybrid switch is shown in Fig. 6 . The contacts are initially closed at time (1). Then, the power source turns on to apply a DC voltage to the circuit at time (2). The contact current increases with a time constant of determined by the circuit inductance and resistance. When the piezoelectric actuator is discharged at time (3), the contact starts to open, the contact current decreases, and the MOSFET current increases in turn. The contact voltage exhibits the voltage of a molten bridge; this value is the same as the turn-on voltage of the SiCMOSFET. After the commutation period, a sufficient gap length is needed to prevent the arc generation between the contacts. Finally, the SiC-MOSFET turns off at time (5), and then, the MOSFET current is commutated to the varistor, which dissipates the inductive energy in the circuit. The interrupting time of the hybrid switch corresponds to the time from (3) to (6), and its duration could be reduced to less than a few milliseconds.

\section{Results and Discussion}

\section{A. Suppression of Making Arc}

To suppress the generation of an arc discharge, the SiCMOSFET is turned on before closing the contacts. Fig. 7 shows the contact voltages with and without turning on the SiC-MOSFET at a current flow of $400 \mathrm{~A}$. Without turning off the SiC-MOSFET, the contact voltage at time zero is equal to the circuit voltage of $20 \mathrm{~V}$. As the gap length decreased, an arc discharge was generated at 3.4 $\mathrm{ms}$, and the contact voltage fluctuated and dropped to approximately $16 \mathrm{~V}$; this value shows the arc voltage. At time $5.1 \mathrm{~ms}$, the contacts seemed to become attached to each other, and the contact voltage gradually decreased to $0 \mathrm{~V}$.

In the case that the SiC-MOSFET was turned-on before closing, the contact voltage or the turn-on voltage of SiCMOSFET was $3.5 \mathrm{~V}$ at a current flow of $400 \mathrm{~A}$. The contact voltage decreased to $2.0 \mathrm{~V}$ at time $3.4 \mathrm{~ms}$, because a part of the current flowed in the contacts. During the closing process, no arc discharge was generated.

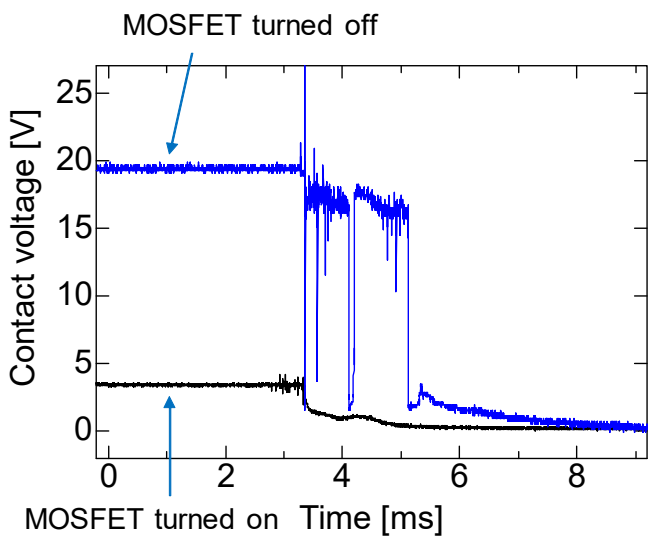

Fig. 7 Contact voltages with and without turning on the SiC-MOSFET during closing process of the hybrid switch.

\section{B. Suppression of Breaking Arc and Arc-free Interruption}

The detailed changes in contact voltage and current waveforms during the commutation period are shown in Fig. 8. The initial contact current was 400 A. After turning on the SiC-MOSFET, a portion of the contact current flowed into the SiC-MOSFET; therefore, the contact current decreased. When the piezo actuator started to separate the contacts, the contact force began to decrease; therefore, the contact voltage gradually increased. When the maximum temperature of the contact surface reached the melting point, the contact voltage showed the stepwise increase at time $2.3 \mathrm{~ms}$. Because of the decrease of the rate of increase of the contact voltage decreased in the following period, and the contact voltage reached approximately $1.9 \mathrm{~V}$, is below the boiling 
voltage of tungsten $(2.1 \mathrm{~V})$. During the commutation period, arc discharges were not observed.

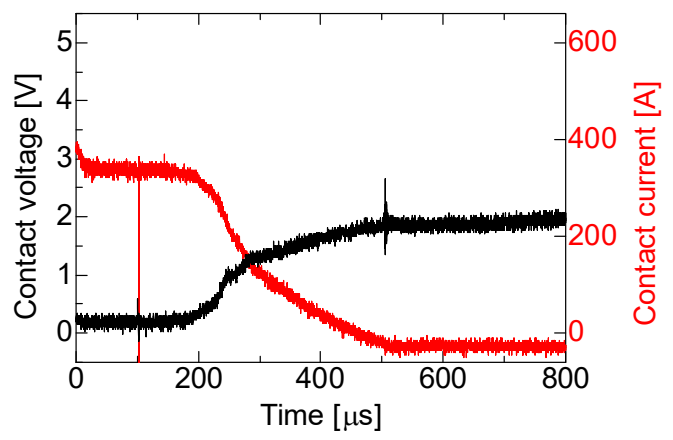

Fig. 8 Contact voltage and current waveforms during commutation of $400 \mathrm{~A}$.

Fig. 9 shows the contact voltage and current waveforms during the commutation of the 500 A current. The stepwise increase and decrease of contact voltage and current were observed after $2.1 \mathrm{~ms}$. At the end of the commutation, a voltage spike was observed at $4.5 \mathrm{~ms}$. The peak voltage exceeded $5 \mathrm{~V}$; thus, the transient breakdown or an arc discharge was generated at this time. The duration of the discharge was short, and the contact voltage reached $2.5 \mathrm{~V}$, exceeding the boiling voltage of tungsten. From these experiments, the maximum arc-free commutation current is $400 \mathrm{~A}$ for the current parameters of the hybrid switch.

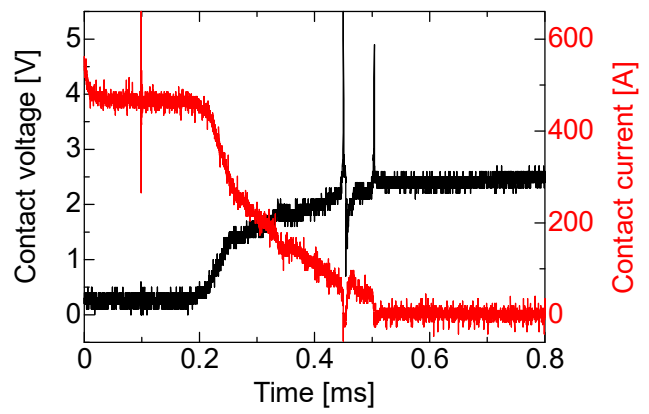

Fig. 9 Current commutation of 500 A DC with short duration arc.

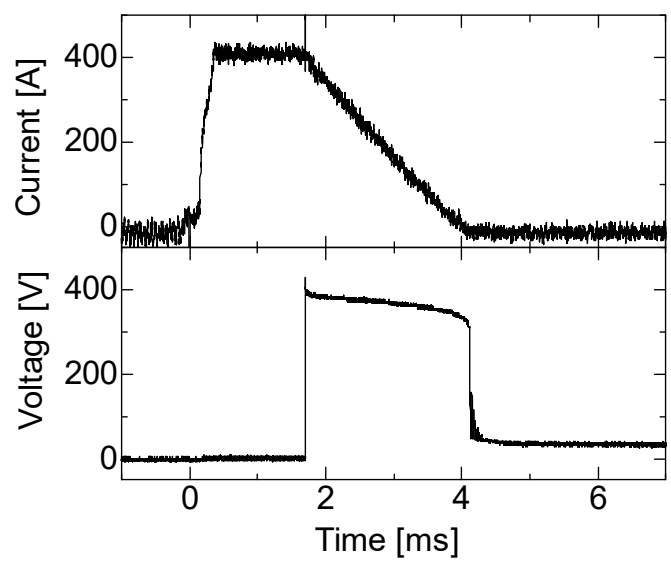

Fig. 10 Contact current and voltage waveforms at arc-free current interruption of $400 \mathrm{~A}$.

The arc-free current interruption of 400 A was demonstrated as shown in Fig. 10 [11]. The switch current, which is the same as the contact current at this period, started to flow at time $0 \mathrm{~ms}$, then reached $400 \mathrm{~A}$ at time $0.4 \mathrm{~ms}$. The commutation period is within $0.3 \mathrm{~ms}$, and contact voltage is below $3 \mathrm{~V}$, as shown in Fig. 8; thus, detailed change in the contact voltage is not observed in Fig. 10. At time $1.7 \mathrm{~ms}$, the SiC-MOSFET was turned off, and the switch voltage increased to $400 \mathrm{~V}$, which is the limiting voltage of the varistors. The inductive energy of the circuit was dissipated in the varistor, and the switch current gradually decreased to zero. The interrupting time of 400 A was $2.4 \mathrm{~ms}$, without generating arc discharges.

\section{Conclusion}

Arc-free on/off switching of 400 A direct current was demonstrated using a hybrid DC switch which consists of tungsten-clad copper contacts with a SiC-MOSFET module and varistors. The tungsten part of the contacts increases the boiling voltage of the contacts, and the copper part decreases the maximum temperature at the contact spot. Both the making and breaking arc discharges were suppressed by this hybrid switch. The commutation period during the opening process of the switch was below $0.3 \mathrm{~ms}$, and the current interrupting period was $2.4 \mathrm{~ms}$ for $400 \mathrm{~A}$.

\section{Acknowledgement}

This work was supported by JSPS KAKENHI Grant Number JP18H01420.

\section{References}

[1] V. A. Prabhala, B. P. Baddipadiga, P. Fajri, and M. Ferdowsi, "An Overview of Direct Current Distribution System Architectures \& Benefits," Energies, Vol. 11, 2463, 2018.

[2] J.C. Ferreira, V. Monteiro, J.L. Afonso, and A. Silva, "Smart Electric Vehicle Charging System," IEEE Intelli. Vehicles Sympo. (IV), pp. 758-763, 2011.

[3] E. Skjong, E. Rodskar, M. Molinas, T.A. Johansen, J. Cunningham, "The Marine Vessel's Electrical Power System: From its Birth to Present Day," Proc. IEEE, Vol. 103 , No. 12 , pp. $2410-2424,2015$.

[4] P. J. Theisen, S. Krstic, "270-V DC Hybrid Switch," IEEE Trans. CHMT, Vol. 9, No. 1, pp. 97-100, 1986.

[5] S. Greitzke, and M. Lindmayer, Commutation and Erosion in Hybrid Contactors Systems," IEEE Trans. CHMT, Vol. 8, No. 1, pp. 34-39, 1985.

[6] R. Nakayama, C. Ou, S. Zen, and K. Yasuoka, "Dielectric strength of electric contacts after short-duration arc in a hybrid DC circuit breaker," IWHV 2018, ED-18-095, 2018.

[7] T. Morita, "ArcFree Technology - Toward a DC Civilization. Internet," https://www.sonycsl.co.jp/tokyo/3088/, 2015.

[8] R. Holm, "Electric Contacts," Fourth edition, Springer Verlag, 1967.

[9] K. Yasuoka, Y. Tsuboi, T. Hayakawa, and N. Takeuchi, "Arcless Commutation of a Hybrid DC Breaker by Contact voltage of Molten Metal Bridge," IEEE Trans. CPMT, Vol. , No. 99, pp. 1-6, 2017.

[10] P.G. Slade, "Electrical Contacts: Principles and Applications," Second Edition, CRC Press, p. 586, 2017.

[11] Y. Yamada, M. Chen, and K. Yasuoka, "Development of Copper-Tungsten Clad-contacts for 400 A arc-less Switching of Hybrid DC Switch", IEEJ Trans. PE, Vol. 139, No. 9, pp. 592-597, 2019. (in Japanese) 